Michał Kokowski

ORCID 0000-0002-5389-9051

Instytut Historii Nauki im. Ludwika i Aleksandra Birkenmajerów

Polskiej Akademii Nauk (Warszawa - Kraków, Polska)

michal.kokowski@gmail.com

\title{
Wprowadzenie do tematyki \\ sesji roboczej „Polskie czasopisma naukowe z dyscyplin: «historia i filozofia nauki» oraz «naukoznawstwo» - aktualne wyzwania" \\ (Kraków, 25 czerwca 2019 r.) i konkretne propozycje rozwiązań organizacyjno- -redakcyjnych i legislacyjnych
}

\begin{abstract}
Abstrakt
W artykule przedstawiono wprowadzenie do tematyki sesji roboczej „Polskie czasopisma naukowe z dyscyplin: «historia i filozofia nauki» oraz «naukoznawstwo» - aktualne wyzwania", zorganizowanej przez Komisję Historii Nauki PAU w Krakowie w dniu 25 czerwca 2019 r., wraz z konkretnymi propozycjami
\end{abstract}

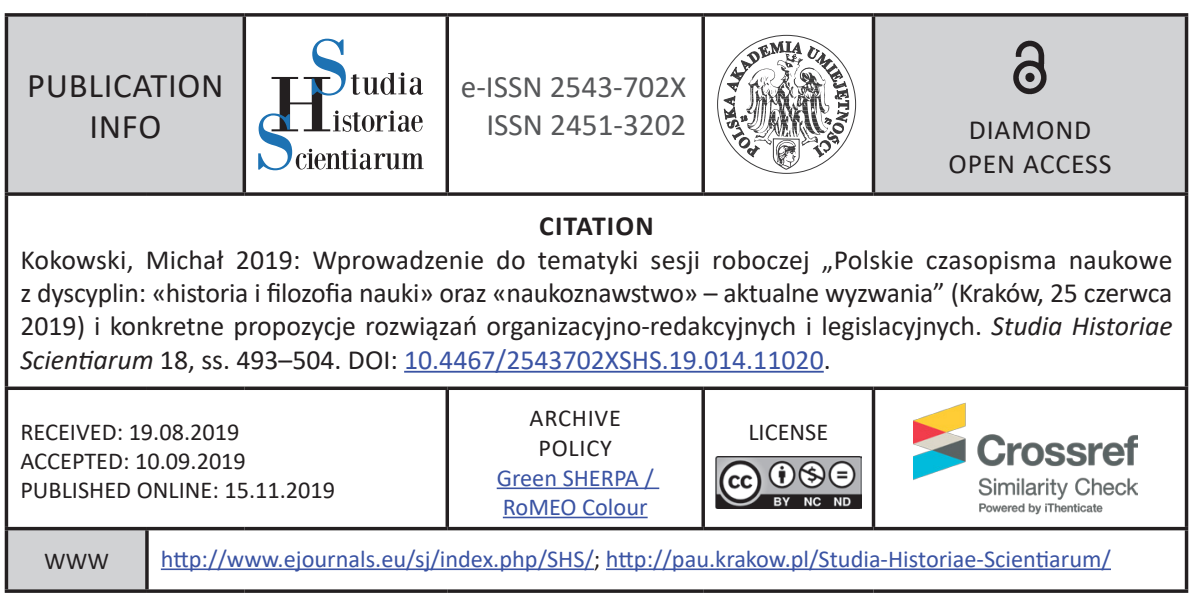


rozwiązań organizacyjno-redakcyjnych dla czasopism i wydawnictw oraz rozwiązań legislacyjnych dotyczących zasad ewaluacji czasopism.

Słowa kluczowe: sesja robocza, polskie czasopisma nankowe, polskie wydawnictwa nankowe, historia i filozofia nanki, naukoznawstwo, polski system ewaluacji czasopism naukonych, postulaty rozwiazan organizacyjno-redakcyjnych dla czasopism i wydawnictw, postulaty zmian legislacyjnych, Polska Akademia Umiejetności, Komisja Historii Nauki PAU

\title{
An introduction to the topic of the Working Session
}

\section{"Polish scientific journals from disciplines:} «history and philosophy of science» and «science of science»- current challenges" (Kraków, 25 June 2019) and specific proposals for organizational, editorial and legislative solutions

\begin{abstract}
The article presents an introduction to the topic of the Working Session "Polish scientific journals from disciplines: «history and philosophy of science» and «science of science» - current challenges" organized by the PAU Commission on the History of Science in Kraków on 25 June 25 2019, along with specific proposals of organizational and editorial solutions for journals and publishing houses, as well as of legislative solutions regarding the principles of journal evaluation.

Keywords: working session, Polish scientific journals, Polish publishing houses, history and philosophy of science, science of science, Polish system of evaluation of scientific journals, postulates of organizational and editorial solutions, postulates of legislative changes, Polska Akademia Umiejetności (PAU), PAU Commission on the History of Science
\end{abstract}




\section{Kwestie podstawowe}

Powodem zorganizowania sesji jest obowiązujące w Polsce ustawodawstwo dotyczące nauki i szkolnictwa wyższego (tzw. ustawa 2.0), w tym aktualny podział dyscyplin naukowych i aktualny mechanizm ewaluacji publikacji naukowych ${ }^{1}$.

\subsection{Aktualny podział dyscyplin naukowych}

Przywołane w tytule dyscypliny bistoria i filozofia nauki oraz naukoznawstwo nie funkcjonują w polskim systemie dyscyplin naukowych, jako samodzielne dyscypliny naukowe. Nie mają też takiego statusu ani bistoria nauki (która jest poddyscypliną historii), ani filozofia nauki (to poddyscyplina filozofir), ani bistorie poszczególnych dyscyplin (to poddyscypliny poszczególnych dyscyplin).

Status naukoznawstwa - które powstało w Polsce w latach 1910-1930 za sprawą lwowsko-warszawskiej szkoły filozoficznej i Kasy im. Józefa Mianowskiego - jest jeszcze bardziej rozmyty, gdyż dyscyplina ta powstaje na skrzyżowaniu problematyki badawczej historii nauki (w tym historii organizacji instytucji naukowych), filozofii nauki, socjologii wiedzy naukowej, polityki naukowej, ekonomii nauki, komunikacji naukowej, scientometrii, bibliometrii etc. ${ }^{2}$

W systemie dyscyplin OECD, obok takich dyscyplin jak np. historia, filozofia oraz etyka, istnieje samodzielna dyscyplina bistoria i filozofia nauki $i$ techniki (bistory and philosophy of science and technology). Należy ona do nauk humanistycznych, sekcja filozofia, etyka i religia, podsekcja historia i filozofia nauki i techniki. Ponadto historie poszczególnych dyscyplin zaliczane są do tychże dyscyplin. W systemie dyscyplin OECD nie ma jednak dyscypliny naukoznawstwo (science of science, science studies) ${ }^{3}$.

Scopus i WoS klasyfikuja czasopisma w zasadzie zgodnie z systemem dyscyplin OECD, dlatego w Scopus i WoS - obok czasopism zaliczanych np. do dyscyplin historia, filozofia, etyka - istnieja czasopisma

1 Zob. Kancelaria Sejmu 2018; MNiSW 2018a; 2018b; 2019b; OECD 2007.

2 Zob. Kokowski 2015a; 2015e.

${ }^{3} \mathrm{~W}$ pierwotnym projekcie tzw. ustawy 2.0 przyjmowano system dyscyplin OECD (i był to jeden z ważniejszych argumentów przemawiających za przyjęciem ustawy 2.0) - zob. Kancelaria Sejmu 2017, Druk 2446-uzasadnienie, ss. 11-12. 
zaliczane do dyscypliny historia i filozofia nauki $i^{4}$, nie ma jednak czasopism zaliczanych do naukoznawstwa.

Tego typu sytuacja sprawia, że z dużym stopniem prawdopodobieństwa można założyć, iż problematyka czasopism zajmujących się dyscyplinami: historia i filozofia nauki i techniki oraz naukoznawstwo, a także problematyka kultury cytowania w tych dyscyplinach zostały zmarginalizowane podczas prac ministerialnych zespołów eksperckich ds. czasopism (zarówno ds. historii, filozofii, jak i wielu innych dyscyplin). Wynikiem tego może być zaniżona ocena punktowa czasopism z tych dyscyplin względem ocen punktowych czasopism zaliczanych do dyscypliny bistoria i dyscypliny filozofia oraz innych samodzielnych dyscyplin naukowych (bowiem o ocenie czasopism z dyscyplin historia i filozofia nanki i techniki oraz naukoznawstwo decydowały z równą wagą różne ministerialne zespoły ekspertów) ${ }^{5}$.

Jednakże z analiz elesperckich opartych na badaniu treści publikacji, a nie liczby cytowań publikacji wiadomo, że czasopisma (także polskie) zaliczane do dyscyplin: historia i filozofia nauki i techniki oraz naukoznawstwo pełnią bardzo ważną rolę kulturotwórczą, nie wolno więc deprecjonować tej roli w polskim modelu ewaluacji nauki (poprzez zaniżanie punktacji takich czasopism) ani pomijać dorobku tych dyscyplin w rozwijaniu polskiego modelu ewaluacji nauki (a działo się tak dotąd) ${ }^{6}$.

\subsection{Podstawowe komponenty czasopisma}

W racjonalnym rozwijaniu czasopism naukowych należy zwrócić uwagę na pięć podstawowych komponentów czasopisma:

1) treść czasopisma;

2) przyjęte w czasopiśmie rozwiązania techniczne (używanie DOI, ORCID oraz licencji wydawniczych CC; obecność w bazie SherpaRomeo, informującej o prawach wydawniczych i zasadach tzw. samoarchiwizowania czasopisma; współpraca z Crossref);

3) przyjęte przez czasopismo procedury recenzyjne (zgodność z zasadami $\mathrm{COPE}^{\top}$ );

${ }^{4}$ W systemie dyscyplin OECD to historia i filozofia nanki i techniki.

5 Zob. MNiSW 2019a.

${ }^{6}$ Kokowski 2015a; 2015d; 2015e.

7 Zob. stronę internetową Committee on Publication Ethics - https://publicationethics.org. 
4) obecność w bazach indeksacyjnych lub bibliotekach czasopism (Scopus, WoS, DOAJ, ERIH+, Index Copernicus International ${ }^{8}$ ) i na liście laureatów konkursu MNiSW „Wsparcie dla czasopism naukowych" (i osiagnięty wynik tego konkursu) etc.;

5) cytowalność czasopisma w różnych bazach (Scopus, WoS, Google Scholar, Index Copernicus International etc.).

\subsection{Aktualny mechanizm ewaluacji czasopism naukowych}

Mechanizm ten oparty jest na niekrytycznej ocenie bibliometrycznej publikacji naukowych i prymacie czasopism indeksowanych w Scopus i WoS, w tym niekrytycznym zliczaniu cytowań czasopism w tych bazach. W mechanizmie tym nie liczy się treść publikacji. W przyjętym przez MNiSW modelu punktowej oceny działalności naukowej pominięto także wycenę punktowa prac redakcyjnych (administracyjnych, edytorskich, recenzyjnych, statystycznych, informatycznych), włącznie z rolą redaktora naukowego tomu czasopisma.

Obowiązujące w Polsce ustawodawstwo dotyczacce ewaluacji dokonań naukowych ma bardzo poważną wadę, abstrahuje bowiem od wyników badań naukowych zintegrowanego naukoznawstwa, do którego zalicza się konglomerat dyscyplin: historia nauki (w tym historia organizacji instytucji naukowych), filozofia nauki, socjologia wiedzy naukowej, psychologia wiedzy naukowej, polityka naukowa, ekonomia nauki, komunikacja naukowa, naukometria, bibliometria etc. Wspomniana bibliometria jest tylko jednym z wymiarów naukoznawstwa i nie wolno go fetyszyzować - co od lat dzieje się w polskim systemie ewaluacji publikacji naukowych.

\subsection{Niedostateczny stopień nasycenia baz indeksacyjnych Scopus i WoS}

Badaczom, specjalizującym się w analizach bibliometrycznych, wiadomo m.in., że bazy Scopus i WoS w przypadku dyscyplin humanistycznych i społecznych w innych językach niż język angielski nie mają

8 Por. wyniki ewaluacji polskich czasopism z historii nauki, historii, filozofii nauki oraz naukoznawstwa z lat 2014-2017 w polskiej bazie indeksacyjnej Index Copernicus International (nie powinno się ignorować tego typu danych w ocenie ministerialnej polskich czasopism) - zob. Kokowski 2019 (w czasie sesji nie były jeszcze znane wyniki ministerialnej ewaluacji czasopism z 3 lipca 2019 r.). 
dostatecznego nasycenia publikacjami (czasopismami, a tym bardziej książkami).

Uznanym na świecie warunkiem używania baz indeksacyjnych w ewaluacji badań naukowych jest przekroczenie progu 50\% nasycenia. W przypadku nauk humanistycznych i społecznych nasycenie baz Scopus i WoS jest jednak znacznie mniejsze. Dlatego właśnie cytowania w bazach Scopus i WoS nie powinny być używane jako główne narzędzie oceny prac naukowych.

W celu uniknięcia niedomówień w tym punkcie, należy dobrze rozumieć, czym jest nasycenie bazy indeksacyjnej publikacjami.

Zauważmy więc na wstępie, że publikacja indeksowana w danej bazie może cytować publikacje już indeksowane przez tę bazę, a także publikacje, które nie są indeksowane w tej bazie. Wiedząc to, przez nasycenie bazy indeksacyjnej rozumiemy iloraz liczby cytowanych publikacji indeksowanych w bazie indeksacyjnej i ogólnej liczby publikacji wymienianych w bibliografiach, tzn. iloraz liczby publikacji indeksowanych i liczby publikacji nieindeksowanych w danej bazie, przemnożony przez $100 \%$.

W ewaluacji czasopisma w określonej bazie liczą się jedynie te cytowania, które pojawiają się w publikacjach (czasopismach, ewentualnie książkach) już indeksowanych przez tę bazę, a pominięte zostają cytowania publikacji, które nie sa indeksowane w tej bazie, choć mogą być one bardzo istotne w sensie merytorycznym; pociaga to za sobą deprecjonowanie czasopism zajmujących się problematyką lokalną (np. polska) i opartą na źródłach archiwalnych (gdyż nie sq one indeksowane w bazach).

Pomimo wskazanych problemów dotyczących kwestii cytowań w bazach indeksacyjnych, należy jednak sprawić przy pomocy przemyślanych działań organizacyjnych, by jak największa liczba czasopism była obecna w tych bazach, gdyż umożliwia to łatwiejsze odnalezienie publikacji w zasobach internetowych.

\subsection{Patologie cytowań}

Badaczom specjalizującym się w analizach naukoznawczych (w tym bibliometrycznych) wiadomo, że istnieje wiele bardzo poważnych nieprawidłowości - patologii cytowań. Zalicza się do nich m.in. kradzieże cytowań; brak właściwych cytowań; zjawisko niecytowania publikacji, 
np. polskich („,bo z definicji sa rzekomo «gorsze» od publikacji zagranicznych"); niewłaściwe, bardzo ułomne zliczanie cytowań przez bazy indeksacyjne (spowodowane brakiem lub wadliwością metadanych plików) 9 .

\subsection{Gdzie można i należy publikować - wskazanie redaktorów uznanych na świecie czasopism $\mathrm{z}$ historii nauki, techniki i medycyny}

W kontekście deprecjonowania znaczenia nauki lokalnej, skupionej na analizie polskiej kultury, należy przypomnieć tezę głoszoną przez siedemdziesięciu czterech redaktorów reprezentujących pięćdziesiąt sześć sztandarowych czasopism na świecie z historii nauki, techniki oraz medycyny (czasopisma te są obecne w bazach Scopus, WoS, ERIH+ etc.). Brzmi ona następująco:

Great research may be published anywhere and in any language. Truly groundbreaking work may be more likely to appear from marginal, dissident or unexpected sources, rather than from a well-established and entrenched mainstream (Cool et al. 2009, s. 2).

Znakomite prace mogą być publikowane gdziekolwiek i w dowolnym języku. Jest bardziej prawdopodobne, że prawdziwie przełomowa praca pojawi się w ubocznych [peryferycznych], innych niż powszechnie przyjęte źródłach niż w rozwiniętym i ściśle ustalonym głównym nurcie badań [tłum. M.K., cytowane za: Kokowski 2015b, s. 176, tu dodano słowo „peryferycznych”].

9 Zob.: Kokowski 2015b, ss. 155-169; 2015c. Odnośnie do kwestii zliczania cytowań czasopisma Studia Historiae Scientiarum w czasopismach już indeksowanych w bazie Scopus, efektywność tej bazy wynosi aktualnie 21-27\% (tzn. Scopus nie wie o istnieniu większości cytowań!); wiąże się to z bardzo niska jakością zapisu bibliografii w czasopismach cytujących Studia Historiae Scientiarum i bardzo niską jakością metadanych tych czasopism. 


\subsection{Rodzimy paradoks: Polskie specjalności naukowe a ocena polskich czasopism}

W tematyce związanej ściśle z polską kultura (np. polonistyka, historia Polski, historia nauki polskiej) rodzime czasopisma, choć z reguły nie są indeksowane w bazach WoS i Scopus, są najważniejszymi tego typu na świecie (Kokowski 2015b, s. 177).

Nie jest to wcale dziwne, bowiem nigdzie indziej na świecie nie ma dostatecznie dużej liczby badaczy, którzy zajmują się taką problematyka. Co za tym idzie, tego typu polskie czasopisma powinny być wysoko oceniane w ewaluacji czasopism. Jest jednak inaczej:

Mamy tu do czynienia z kuriozalną sytuacja. Konstytucja Rzeczypospolitej Polskiej i ustawa o języku polskim uważają kulturę polską za najwyższe dobro państwa - a obowiązujący model ewaluacji traktuje ją bezpardonowo jako coś gorszego (bo z definicji publikacje z tego zakresu zasługuja na mniejszą liczbę punktów niż wytwory kultury uniwersalnej) (Kokowski 2015b, s. 177) ${ }^{10}$.

\subsection{Konkluzja}

Ze względu na: a) niedostateczny stopień nasycenia baz indeksacyjnych Scopus i WoS w przypadku dyscyplin humanistycznych i społecznych oraz b) liczne patologie cytowań, w ocenie czasopism naukowych dyscyplin humanistycznych i społecznych należy skupiać uwagę nie na cytowaniach, lecz na analizie treści publikacji oraz przyjętych w czasopismach rozwiązaniach technicznych i procedurach recenzyjnych.

\section{Kwestie pragmatyczne}

Niezależnie od oceny aktualnego systemu ewaluacji polskich publikacji naukowych oraz czy zostanie w Polsce zmieniony system ewaluacji nauki, wszystkie polskie czasopisma naukowe - niezależnie czy zajmują się problematyką uniwersalna, globalną czy lokalną - podlegają rygorom

10 Zob. Konstytucja Rzeczypospolitej Polskiej z dnia 2 kwietnia 1997 r.: art. 6.1; Ustawa z dnia 7 października 1999 r. o języku polskim, preambuła, art. 1.1 i 3.1.5. 
aktualnego systemu ewaluacji, opartego na prymacie cytowań i to najlepiej cytowań widocznych w bazach Scopus i WoS. Rozwijając w Polsce pełnoprawne czasopismo naukowe, nie można abstrahować od tego fundamentalnego faktu legislacyjnego.

\subsection{Przeciwdziałanie stosunkowo niskiej cytowalności polskich publikacji z zakresu nauk humanistycznych i społecznych}

Mając na względzie fakt wysokiego statusu cytowalności w bazach Scopus i WoS w polskim systemie ewaluacji działalności naukowej, należy przyjąć do wiadomości, że aktualna cytowalność polskich publikacji z zakresu nauk humanistycznych i społecznych (w tym czasopism i książek z dyscyplin historia i filozofia nauki $i$ techniki $i$ naukoznawstwo) jest w tych bazach relatywnie niska i dla dobra polskiej nauki należy to jak najszybciej zmienić (metodami agodmymi z etyka i prawem).

Chcąc zaradzić niskiej cytowalności polskich czasopism (także w bazach Scopus i WoS), należy jak najszybciej unowocześnić procedury wydawania publikacji naukowych w Polsce. Obowiązek ten spoczywa zarówno na polskich wydawnictwach naukowych i redakcjach czasopism naukowych, jak i na autorach publikacji.

Unowocześnienie to powinno polegać na:

a) wdrożeniu identyfikatorów DOI i ORCID;

b) otwarciu polskich publikacji na świat: chodzi tu o rozszerzenie tematyki czasopism także o problematykę zagraniczną i wydawanie czasopism także w językach kongresowych (nie istnieje bowiem „nauka lokalna” w stu procentach niezależna od „nauki globalnej” czy „nauki uniwersalnej”) oraz wdrożenie przez wydawnictwa naukowe i redakcje czasopism naukowych idei otwartej nauki (w oparciu o licencje wydawnicze CC);

c) wdrożeniu przez wydawnictwa naukowe i redakcje czasopism naukowych idei rzetelnego cytowania (należy rzetelnie cytować wszystkie publikacje, jakie autor wykorzystuje w trakcie przygotowywania własnej publikacji; cytowanie musi zawierać komplet informacji bibliograficznych włącznie z identyfikatorem DOI, linkiem dostępu do pliku elektronicznego);

d) wdrożeniu przez wydawnictwa naukowe i redakcje czasopism naukowych zasad etyki wydawniczej COPE (Committee on Publication Ethics); 
e) wdrożeniu przez wydawnictwa i redakcje czasopism naukowych procedury rzetelnego przygotowywania metadanych publikacji;

f) sprawieniu, by informacja o przyjętej w czasopiśmie tzw. polityce samoarchiwizowania umieszczona była w międzynarodowej bazie Sherpa-Romeo;

g) włączeniu jak największej liczby polskich czasopism do baz Scopus, WoS, DOAJ, Index Copernicus International, ERIH+;

h) uaktywnieniu autorów publikacji naukowych, by przestrzegali zasady rzetelnego cytowania publikacji i promowali swój dorobek w sieci internetowej (Researchgate, Academia.edu etc.).

\subsection{Przeciwdziałanie deprecjonowaniu w Polsce pracy redaktorskiej}

Chcąc zaradzić dotkliwemu deprecjonowaniu w Polsce pracy redaktorskiej (niemal z reguły pracy wykonywanej nieodpłatnie), należy ją właściwie dowartościować poprzez dobrze przemyślane akty legislacyjne.

Jeśli w modelu ewaluacji działalności naukowej utrzymana będzie idea oceny punktowej pracy naukowej, istnieje konieczność wprowadzenia punktacji za prace redakcyjne redaktorów czasopism naukowych (sekretarza, redaktorów działów, redaktora statystycznego, z-cy redaktora naczelnego, redaktora naczelnego), recenzentów wewnętrznych czasopism naukowych oraz recenzentów zewnętrznych czasopism naukowych ${ }^{11}$. Hierarchia punktacji uzależniona powinna być od rangi czasopisma mierzonej obecnością w Scopus, WoS, DOAJ, Index Copernicus, ERIH+ oraz ministerialnym programie WCN (Wsparcie Czasopism Naukowych). Ponadto fakt bycia redaktorem naukowym tomu czasopisma należy traktować na takich samych prawach, jak fakt bycia redaktorem naukowym monografii zbiorowej.

\section{Bibliografia}

Cook, Hal; et al. 2009: Journals under Threat: A Joint Response from History of Science, Technology and Medicine Editors. Medical History 53(1), ss. 1-4. Available online: http://www.ncbi.nlm.nih.gov/pmc/articles/PMC2629173/ pdf/medhis530100a01.pdf.

11 Należy przypomnieć, że zasady COPE zezwalają na wykonywanie zarówno tzw. recenzji wewnętrznych, jak i tzw. recenzji zewnętrznych. 
Kancelaria Sejmu 2017: Rządowy projekt ustawy - Prawo o szkolnictwie wyższym i nauce. Druk nr 2446. Pliki „,ustawa.docx”, „2446-uzasadnienie.docx”; „2446-cz. I.pdf”; „2446-cz. II.pdf”. Dostęp online: https://www.sejm.gov.pl/ Sejm8.nsf/druk.xsp?nr=2446; http://orka.sejm.gov.pl/Druki8ka.nsf/0/6C22FAA797502236C125826E0022D98C/\%24File/2446-ustawa.docx; http:// orka.sejm.gov.pl/Druki8ka.nsf/0/6C22FAA797502236C125826E0022D98C/\%24File/2446-uzasadnienie.docx; http://orka.sejm.gov.pl/ Druki8ka.nsf/0/6C22FAA 797502236C125826E0022D98C/\%24File/2446-cz.\%20I.pdf; http://orka.sejm.gov.pl/Druki8ka.nsf/0/6C22FAA797502236C125826E0022D98C/\%24File/2446-cz.\%20II.pdf.

Kancelaria Sejmu 2018: Ustawa z dnia 20 lipca 2018 r. - Prawo o szkolnictwie wyższym i nauce (tekst ujednolicony). Dz.U. 2018 poz. 1668. Dostęp online: http://prawo.sejm.gov.pl/isap.nsf/download.xsp/WDU20180001668/U/ D20181668Lj.pdf.

Kokowski, Michał 2015a: Szkic aktualnej debaty nad naukometria i bibliometria w Polsce i zapomniane naukoznawstwo. Prace Komisji Historii Nauki PAU 14, ss. 117-134. Dostęp online: http://www.ejournals.eu/sj/index.php/PKHN-PAU/article/download/6458/6383.

Kokowski, Michał 2015b: Jakiej naukometrii i bibliometrii potrzebujemy w Polsce? Prace Komisji Historii Nauki PAU 14, ss. 135-184. Dostęp online: http:// www.ejournals.eu/sj/index.php/PKHN-PAU/article/download/6460/6384.

Kokowski, Michał 2015c: Bibliografia naukometryczno-bibliometryczno-informetryczna (wybór). Prace Komisji Historii Nanki PAU 14, ss. 185-266. Dostęp online: http://www.ejournals.eu/sj/index.php/PKHN-PAU/article/download/6461/6385.

Kokowski, Michał 2015d: Uniwersytet nowego humanizmu. Zagadnienia Naukoznawstwa 1 (203), ss. 17-43. Dostęp online: http://yadda.icm.edu.pl/yadda/ element/bwmeta1.element.desklight-c111edb6-bcda-4b40-b1e1-5fc2925b$19 \mathrm{cb} / \mathrm{c} / \mathrm{ZN} 1-2015$ 2-Uniwersytet.pdf.

Kokowski, Michał 2015e: The science of science (naukoznawstwo) in Poland: the changing theoretical perspectives and political contexts - a historical sketch from the 1910s to 1993. Organon 47, ss. 147-237. Dostęp online: http://www. cyfronet.krakow.pl/ n1kokows/Kokowski-Organon-2015.pdf.

Kokowski, Michał 2019: „Wykazy czasopism MNiSW 2017 i 2019”, „ICI Journal Master List 2014-2017" a polskie czasopisma z historii nauki, historii, filozofii nauki oraz naukoznawstwa. Studia Historiae Scientiarum 18, ss. 505-513. DOI: $10.4467 / 2543702 X S H S .19 .015 .11021$.

MNiSW 2018a: Rozporządzenie Ministra Nauki i Szkolnictwa Wyższego z dnia 20 września 2018 r. w sprawie dziedzin nauki i dyscyplin naukowych oraz 
dyscyplin artystycznych. Dostęp online: http://prawo.sejm.gov.pl/isap.nsf/ download.xsp/WDU20180001818/O/D20181818.pdf.

MNiSW 2018b: Zależności między nową klasyfikacją dziedzin i dyscyplin a wcześniej obowiązującym wykazem i systematyką OECD. Dostęp online: https:// konstytucjadlanauki.gov.pl/content/uploads/2018/09/nowy-podzia-dyscyplin-tabela.pdf.

MNiSW 2019a: Zarządzenie Ministra Nauki i Szkolnictwa Wyższego z dnia 25 stycznia 2019 r. w sprawie powołania zespołów doradczych do spraw wykazów czasopism naukowych i recenzowanych materiałów z konferencji międzynarodowych. Dostęp online: http://www.bip.nauka.gov.pl/g2/oryginal/2019_01/9cdf7e8af9521cdbfbce9d96504a5c3a.pdf.

MNiSW 2019b: Rozporządzenie Ministra Nauki i Szkolnictwa Wyższego z dnia 22 lutego 2019 r. w sprawie ewaluacji jakości działalności naukowej. Dz.U. 2019 poz. 392. Dostęp online: http://www.dziennikustaw.gov.pl/du/2019/392/ D2019000039201.pdf.

OECD 2007: Klasyfikacja dziedzin i dyscyplin naukowych według OECD. Dostęp online: https://web.archive.org/web/20070709105133/http://www. oecd.org/dataoecd/36/44/38235147.pdf; htttp://www.ichtj.waw.pl/ichtj/li-

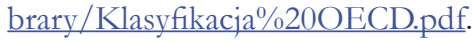

